\title{
Adaptation of the European Union risk assessment protocol for the pre-inventory of Walloon mining waste deposits
}

\author{
C.C. Frippiat Institut Scientifique de Service Public, Belgium \\ N. Stéphenne Institut Scientifique de Service Public, Belgium \\ M. Veschkens Institut Scientifique de Service Public, Belgium \\ D. Pacyna Service Public de Wallonie, Belgium
}

\begin{abstract}
European Union Directive 2006/21/EC requires member states to identify closed mining waste facilities potentially posing a serious threat to human health or environment. A general pre-selection protocol was proposed by an Ad-hoc Group of the Technical Adaptation Committee (TAC) of the directive. The protocol considers several criteria, including the presence of pollutants, the stability of the source, four types of pathways and four receptor components. The Institut Scientifique de Service Public (ISSeP) modified the protocol in order to better account for specific regional conditions. The adaptations proposed for the Walloon Region and described in this paper include the exclusion of some criteria, the calculation of additional criteria and a particular combination of source, pathways and receptors to better represent current risks in the region. This method allowed the pre-selection of the facilities needing further risk analysis.
\end{abstract}

The implementation of the pre-selection is done in a geographic information system (GIS) using existing datasets provided either by European institutions (European Environment Agency) or regional authorities (Walloon Public Services - in French, Service Public de Wallonie). GIS inputs include topographic data (location of settlements, surface waters, terrain, etc.), census figures, protected areas, land use/land cover surfaces, delineation of groundwater bodies (according to the Water Framework Directive) and site data that are specific to the waste facilities under consideration (location, contents, geometry, etc.).

For the application to the Walloon region, ISSeP excluded several criteria of the protocol based on the regional history of mining activities. New criteria were added, including slope of the heap and impact distance in case of failure. This paper discusses the exclusion choices and the relevance of the new criteria for five types of potential risks: air quality, water resources quality, soil quality, human health in case of direct contact, and linked to heap stability. The additional risk to coal heap combustion is also considered but cannot be included in a systematic risk assessment procedure.

Carried out in response to EU Directive 2006/21/EC, the study refers to the protocol proposed by the TAC to inventory closed mining waste facilities. This paper describes its implementation within a GIS based on the European and Walloon datasets and proposes adaptations to deal with regional Walloon specificities. The paper focuses on one risk seen as one of the most relevant in the Walloon case to describe these adaptations in terms of criteria and risk definition. The adaptations have a clear impact on the number of waste facilities pre-selected. At the end of the process, only 30 heaps are selected for further analysis. A detailed investigation of these facilities is planned in the next months in collaboration with the authorities.

\section{$1 \quad$ Introduction}

Each member state in the European Union (EU) has the responsibility of managing waste related to its past mining activities, as agreed in EU Directive 2006/21/EC (European Parliament and Council, 2006). The Institut Scientifique de Service Public has been asked by Walloon authorities to study the risks associated with the closed mining waste facilities (WFs) according to the specifications provided by the EU. Inspired by 
the EU proposed methodology and Walloon particularities, this paper proposes a semi-automatic methodology using a geographic information system (GIS) to select the closed mining waste facilities that can pose a serious risk for environment and human health. This pre-selection will be followed by further analysis to confirm the risks for each facility identified.

Directive 2006/21/EC approved by the European Parliament and the Council on 15 March 2006 proposes a European framework for managing waste from extractive industries (or mining waste directive). This management relies on an assessment of the risk constituted by the presence of extractive waste facilities.

Article 3 (15) of the Mining Waste Directive defines a waste facility as:

" any area designated for the accumulation or deposit of extractive waste, whether in a solid or liquid state or in solution or suspension ... Such facilities are deemed to include any dam or other structure serving to contain, retain, confine or otherwise support such a facility, and also to include, but not be limited to, heaps and ponds."

Following this definition, two main categories of waste facilities can be distinguished: heaps or tips, where waste is mainly stored in solid form, and tailing ponds, in which waste is stored in liquid form or in suspension within a solution. Mining residues are defined as any product or deposit resulting from mining exploration, mining extraction activities and ore processing.

In particular, Article 20 of the Directive requires that

"Member States shall ensure that an inventory of closed waste facilities, including abandoned waste facilities, located on their territory which cause serious negative environmental impacts or have the potential of becoming in the medium or short term a serious threat to human health or the environment is drawn up and periodically updated."

The inventory must include only waste facilities having serious impacts on the environment or on human health. The inventory should be based on an assessment of the current impacts on the environment and the potential impacts on human health and the environment associated with a defect of the waste facility.

The nature and extent of the potential impacts to consider in the inventory will mainly depend on the type of waste contained in the WF. The most common impacts associated with the presence of former mining sites include:

- Impacts on air quality. Dust production by a waste facility can create a risk to human health if inhaled. Gas emissions associated with the combustion of coal heaps can also dangerously impact air quality.

- Impacts on water resources (surface water and/or groundwater), mainly through acid generation or leaching of heavy metals. Acid mine drainage develops in the presence of minerals containing iron sulphides. The associated impacts depend on several factors such as type of sulphides, local geological conditions, the sensitivity of nearby targets and the possibility of dilution or neutralisation of the acidic effluents. Leaching of aluminium, iron and copper can be delayed by $\mathrm{pH}$ neutralisation. On the contrary, the solubility of arsenic, cadmium and zinc can remain high even at neutral $\mathrm{pH}$. The quality of surface waters can also be affected by runoff due to soil and mining waste erosion.

- Impacts on soil quality, as linked to a contamination by heavy metals, for example.

- Impacts on human health associated to a direct contact with the mining waste.

In addition to these continuous impacts, accidental failure could also seriously impact human security. In the Walloon Region, this risk is seen as the most relevant related to closed WFs. As a consequence, the loss of geotechnical stability is the type of accident considered in this paper to illustrate the method developed for a pre-inventory. This loss of stability can be linked either to local slope failure or to the global failure of the waste heap or of the containment dike of a waste pond. The combustion of coal heaps can also, in certain special situations, cause accidents of great magnitude, such as explosions or fires. WFs at risk for 
this specific hazard have been identified by authorities based on qualitative and historical information about mining activities and incident reporting.

The Ad Hoc Group (AHG) created by the Technical Adaptation Committee of the Directive proposed to the Member States a method to carry out a pre-inventory of their closed waste management facilities (Stanley et al., 2011). The AHG interpreted Article 20 of the Mining Waste Directive, and other articles of the Directive, as well as Decision 2009/337/EC (European Commission, 2009), to establish a list of criteria for the classification of waste management facilities in accordance with Annex III of the Mining Waste Directive. The goal of this pre-inventory method is to identify semi-automatically without field investigation the list of WFs in which there is a higher probability to see more serious risks. The main objective of this pre-selection is to decrease the number of WFs to be further analysed and integrated in the complete inventory.

This paper presents the method adopted for the pre-inventory of the risks associated with closed and/or abandoned mining waste facilities in the Walloon region. A preliminary discussion allowed the exclusion of any risk associated with Walloon metal mine waste facilities or Walloon quarry waste facilities. As no abandoned and/or closed tailing pond exists in the Walloon region, the only type of waste facilities needing full risk assessment are coal mine WFs. They are also the most documented facilities. Hence, the paper only focusses on risks associated with coal tips. However, the direct application of the AHG procedure did not allow an efficient screening of the risks associated with Walloon coal tips. The methodology had to be modified in order to adjust to Walloon specificities.

This paper is divided in three sections. The first one refers to the history of the coal mining activities in the Walloon Region and the information used in this paper about coal WF. The second one presents the method proposed by the AHG and discusses the way this method considers the five types of impacts mentioned in this Introduction. In this second section the theory of the methodology is adapted in terms of interdependence between criteria. The new method assesses the risk by combining source, pathway and target in a specific workflow different for each type of impact. The third section illustrates the adaptation of the original protocol for one of the five impacts, the geotechnical failure. New criteria have been defined, and the number of WFs pre-selected is much lower than when using the original protocol.

\section{Coal mines and coal waste in the Walloon Region}

\subsection{A brief history of coal mining in Belgium}

Coal exploitation started in Belgium as early as in the Middle Ages thanks to coal outcrops in the region of Liège and in the Borinage (from Charleroi to La Louviere). At its independence in 1830, Belgium was already the second largest coal producer in the world after England, with 307 coal mines. Between 1831 and 1850, coal production volumes multiplied by a factor of two. In 1845 Belgian collieries employed 46,000 miners. During the first half of the nineteenth century, Belgium was the only country in Europe, apart from England, where coal mines actually developed. Many mergers occurred during the second half of the nineteenth century, leading to increased profitability. In 1900, national coal production reached 23.5 million tonnes, compared with 18 million in 1880 .

At that time, total production started to decline. The decision to close coal mines was taken in two steps. First, coal mines of the eastern part of the Walloon region closed in the 1960s. Closure of coal mines in the rest of the region followed. In 1984 the last operating coal mine in the Liege area closed. Total extracted coal in the Walloon region is estimated at more than 2 billion tonnes.

\subsection{Coal waste and waste facilities}

The main type of waste from coal extraction consists of lumps or stones ranging in size from $2 \mathrm{~mm}$ to $2 \mathrm{~m}$. These materials are generally stacked to form heaps. In its Decree of March 16, 1995, the Walloon government lists about 300 coal tips, representing a total weight in the order of 700 million tonnes. The remaining coal content usually ranges between $5 \%$ and $10 \%$, leading to a total amount of coal of between 
26 million and 52 million tonnes. These coal tips are mainly located along the valleys of the Sambre and Meuse rivers, over a territory that covers no more than $1,000 \mathrm{~km}^{2}$. Existing heaps have an average surface area of $70,000 \mathrm{~m}^{2}$ and an average height of $20 \mathrm{~m}$. The maximum surface area is about $800,000 \mathrm{~m}^{2}$ and the maximum elevation does not exceed $80 \mathrm{~m}$.

In order to improve the daily management of abandoned coal heaps, regional authorities have developed an extended database, including both existing heaps and heaps that have been levelled off. Geometric objects in this database are polygons depicting heap ground surface coverage. The polygons are georeferenced within a GIS environment. This database is publicly accessible through the Internet (geologie.wallonie.be) and lists 591 coal heaps classified in five categories. Category 1 corresponds to existing and delineated heaps and identifies 277 sites. Other categories correspond to heaps that have been levelled off and that do not pose any threat with respect to geotechnical stability. Hence, only coals heaps of Category 1 are considered for the pre-inventory.

\section{General methodology for risk assessment}

The general methodology proposed by the AHG (Stanley et al., 2011) to identify abandoned and/or closed waste facilities posing a risk to human health or safety and/or to the environment and the ecosystems is primarily based on 18 general questions that address different key aspects of risk assessment, from the existing situation and current known impacts, to source of hazard, pathways and targets.

Stephenne et al. (2013) describes the input data used in the GIS built to represent this risk assessment. The questions are presented in Table 1 . The methodology considers the five types of risk mentioned in the introduction:

- A chronic risk for air quality.

- A chronic risk for water resources quality.

- A chronic risk for soil quality.

- A chronic risk for human health linked to direct contact with the waste.

- An accidental risk linked to a geotechnical failure of the waste facility.

However, the different types of risks were not examined separately in the original methodology of the AHG. As long as one source of hazard, one pathway and one specific target is present, the methodology leads to the conclusion that the waste facility should be considered as needing further examination. This approach does not link the type of risk with the respective cause of hazard, its mode of transfer, and the presence of potential targets. The original methodology of the AHG was found not directly applicable to the Walloon case, as it did not discriminate any waste facility.

A new methodology was developed, in order to better take into account the specific conditions encountered in the exploitation of mineral resources in the Walloon region. It uses a different approach for risk assessment. Risks are no longer evaluated within a single workflow but rather individually. In addition to the five types of risk accounted for in the methodology of the AHG, the risk associated with burning coal heaps is also seen as important in the Walloon case. Table 2 presents the new methodology. Most of the criteria are taken from the initial protocol of the AHG.

Although not mentioned in Table 2, known impacts related to historical incidents are still considered. In the Walloon region, they are however only associated with burning coal heaps. The risk to soil quality is not explicitly evaluated, as it will be linked to either air or water resources quality. Indeed, soil quality can be impacted by surface deposition of heavy metals or pollutants adsorbed on dust particles emitted by the waste facility or by solubilised pollutants leaching through the waste facility into the ground. Hence, as long as agricultural lands are considered potential targets when assessing the risks to air or groundwater resources quality, a separate assessment of the risks to soil quality is not required. 
Table 1 List of questions of the guidance protocol proposed by the AHG (after Stanley et al., 2011); question numbers correspond to the numbering of the questions in the original protocol of the AHG

\begin{tabular}{|c|c|c|}
\hline Component & Criteria & $\begin{array}{l}\text { Question } \\
\text { Number }\end{array}$ \\
\hline Historical incidents & Does the facility have a current impact on the environment? & Q1 \\
\hline \multirow[t]{3}{*}{ Pollutant content } & Does the waste contain sulphide minerals? & Q2 \\
\hline & Does the waste contain heavy metals? & Q3 \\
\hline & Does the waste contain dangerous chemicals? & Q4 \\
\hline \multirow[t]{3}{*}{ Heap stability } & Is heap surface area larger than $10,000 \mathrm{~m}^{2}$ ? & Q8 \\
\hline & Is heap elevation larger than $20 \mathrm{~m}$ ? & Q9 \\
\hline & Is the slope of the heap foundation larger than $1 / 12$ ? & Q10 \\
\hline \multirow{4}{*}{$\begin{array}{l}\text { Contaminant } \\
\text { transfer within } \\
1 \mathrm{~km}\end{array}$} & Is there a watercourse within $1 \mathrm{~km}$ ? & Q11 \\
\hline & Is there a low permeability layer beneath the facility? & Q12 \\
\hline & Is waste exposed to wind? & Q13 \\
\hline & Is waste uncovered? & Q14 \\
\hline \multirow[t]{4}{*}{$\begin{array}{l}\text { Targets within } \\
1 \mathrm{~km}\end{array}$} & $\begin{array}{l}\text { Is there a human settlement of more than } 100 \text { people within } \\
\qquad 1 \mathrm{~km} \text { of the facility? }\end{array}$ & Q15 \\
\hline & $\begin{array}{l}\text { Is the facility located within } 1 \mathrm{~km} \text { of a water body that is of less } \\
\text { than good status? }\end{array}$ & Q16 \\
\hline & Is there a Natura 2000 site within $1 \mathrm{~km}$ of the waste facility? & Q17 \\
\hline & $\begin{array}{l}\text { Is the waste facility within } 1 \mathrm{~km} \text { of agricultural land or } \\
\text { livestock? }\end{array}$ & Q18 \\
\hline
\end{tabular}

The criteria linked to the risks to the quality of groundwater resources are not maintained in the Walloon methodology. First, considering that the most recent coal heaps in the Walloon region are about 30 years old, any impact on water resources would have been noticed. And most Walloon coal heaps are located in relatively heavily industrialised zones; if groundwater contamination were observed, it would probably be linked to the industrial activity that developed around or on the mining site rather than to the coal heap itself.

A thorough systematic discussion of the other specificities of the Walloon protocol is beyond the scope of this paper. For the sake of brevity, source data and data quality cannot be systematically discussed for each criterion either. Instead, it is proposed to only focus on the assessment of the risk of geotechnical failure, as it proved to be the main discriminating factor when screening Walloon coal mine waste facilities. 
Table 2 Risk-specific methodology and associated criteria used to screen Walloon coal waste heaps

\begin{tabular}{|c|c|c|c|}
\hline Risk & Component & Criteria & $\begin{array}{c}\text { Initial Protocol } \\
\text { Question Number }\end{array}$ \\
\hline \multirow[t]{4}{*}{ Air quality } & Source & Surface area & Q8 \\
\hline & Pathway & Vegetation cover & Q13 \\
\hline & Target & Human population & Q15 \\
\hline & & Agricultural lands & Q18 \\
\hline \multirow{7}{*}{$\begin{array}{l}\text { Geochemical quality of } \\
\text { water resources }\end{array}$} & Source & Surface area & Q8 \\
\hline & & Sulphide minerals & Q2 \\
\hline & & Heavy metals & Q3 \\
\hline & & Dangerous chemicals & Q4 \\
\hline & Target & Water course & Q11 \\
\hline & & Human population & Q15 \\
\hline & & Agricultural lands & Q18 \\
\hline \multirow[t]{5}{*}{ Direct contact } & Source & Surface area & $\mathrm{Q} 8$ \\
\hline & & Sulphide minerals & Q2 \\
\hline & & Heavy metals & Q3 \\
\hline & & Dangerous chemicals & Q4 \\
\hline & Pathway & Vegetation cover & Q14 \\
\hline \multirow[t]{7}{*}{ Geotechnical failure } & Source & Surface area & Q8 \\
\hline & Pathway & Height & Q9 \\
\hline & & Geotechnical factor of safety & / \\
\hline & & Foundation slope & Q10 \\
\hline & Target & Human population & Q11 \\
\hline & & Watercourses & Q15 \\
\hline & & Natura 2000 site & Q17 \\
\hline
\end{tabular}

\section{$4 \quad$ Example application: risk of geotechnical failure}

\subsection{Mechanisms of geotechnical failure}

Geotechnical failure can take the form of a landslide, either remaining confined within the waste heap or extending into heap foundations. In certain cases, depending on the type and level of alteration of the bedrock, heaps can slide as a whole on their foundation ground. Initial movements associated with failure are usually slow, with failure developing over periods ranging from several hours to several days. Landslides are often preceded by warning signs that are easily observable. Other types of failure are waste material liquefaction, surface erosion and gullying and cavitation.

A detailed evaluation of the risks associated with each failure mode cannot be conducted in a systematic fashion but rather requires a detailed examination of each heap under consideration. However, as Walloon 
coal heaps are relatively ancient and should not undergo any variations in applied loads or internal hydraulic conditions, only two failure modes are considered here:

- Slope failure.

- Global slip of the heap on its foundation soil.

These are also the two types of failure modes taken into consideration in the initial protocol of the AHG. The risk associated to surface erosion is also considered negligible, with most heaps being covered by vegetation over significant surface portions.

\subsection{Characterisation of risk components}

\subsubsection{Source}

According to the Health and Safety Executive of United Kingdom (1999), the risk of failure increases with the size of the waste facility. A surface area of $10,000 \mathrm{~m}^{2}$ is proposed as a threshold value, beneath which the impact associated with the presence of the facility will not be considered significant (question Q8 of the protocol, see Table 1). A similar assumption is adopted here: failure associated with a coal heap covering a surface area of less than $10,000 \mathrm{~m}^{2}$ will not be considered significant. This does not mean that the risk of geotechnical failure of small heaps is excluded. It only means that, if such failure occurs, the impacts are likely to be of restricted extent, and potential corrective measures should be limited. Heap size is directly computed within the GIS environment from the database created by regional authorities (see Section 2.2). It appears that most coal heaps cover a surface area larger than the proposed threshold value (Figure 1).
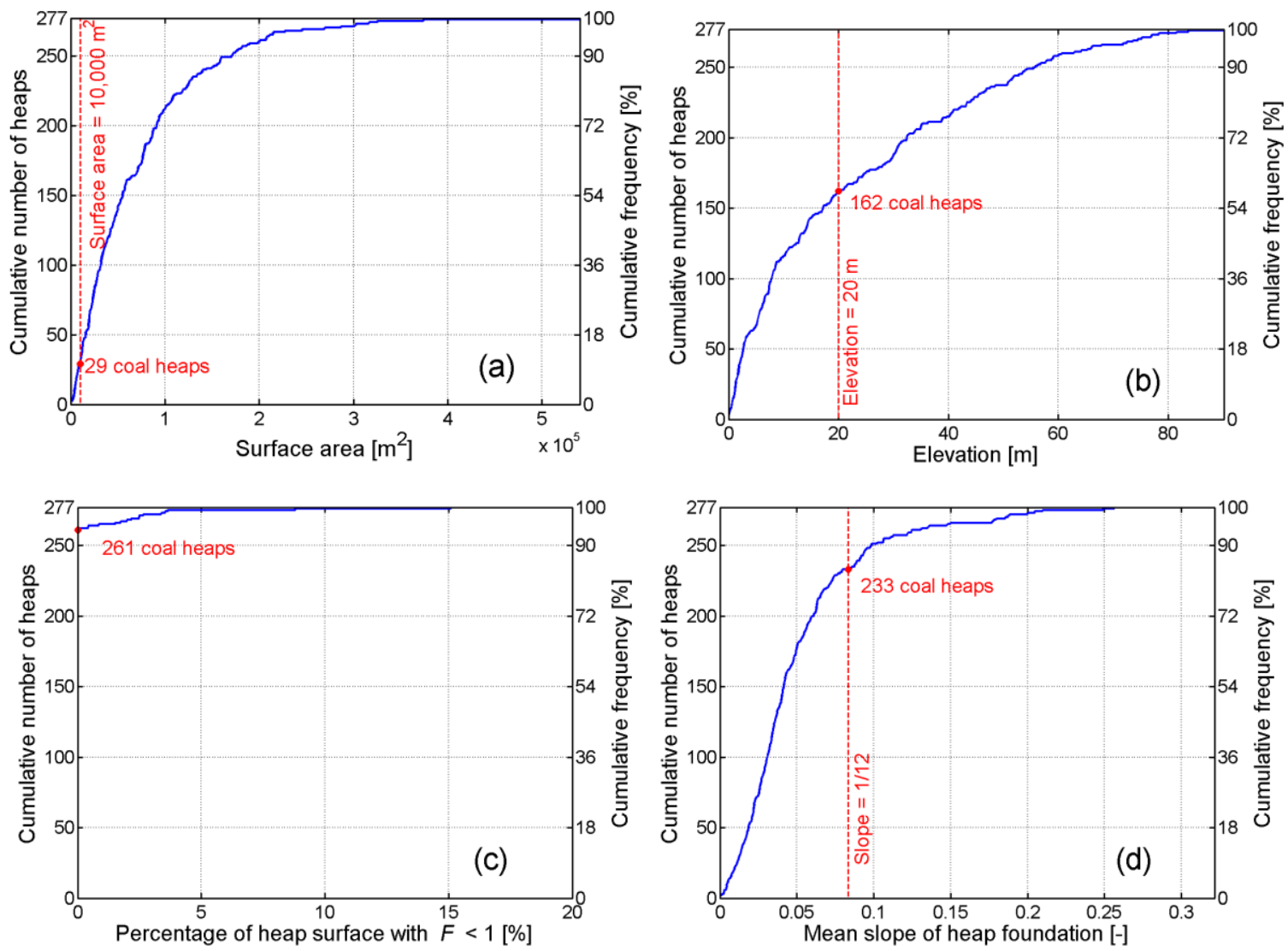

Figure 1 Analysis of geometrical and geotechnical features of Walloon coal heaps; (a) cumulative distribution of coal heap surface area values; (b) cumulative distribution of coal heap height values; (c) cumulative distribution of the percentage of heap surface with $\mathrm{F}<1$; and (d) cumulative distribution of the slope of heap foundation 
Only 29 heaps have a surface area smaller than $10,000 \mathrm{~m}^{2}$. This represents about $10 \%$ of the number of heaps in the Walloon region. This also illustrates that, in the initial protocol of Stanley et al. (2011), question Q8 was not an efficient screening criterion for the Walloon case. A direct application of this criterion of the initial protocol of the AHG would not lead someone to consider that a significant number of coal heaps do not pose any serious threat. In this respect, the pre-selection protocol would fail to meet its objective of decreasing the number of WF needing detailed risk assessment.

\subsubsection{Pathway}

While it could be argued that the pathway component is only linked to the properties of the environment between the source of hazard (i.e. the heap) and potential targets, it is defined here as the set of processes and mechanisms that lead to a displacement of the waste material from the heap to the potential targets. Hence, the parameters and variables described here are geometrical and geotechnical features of the source of hazard but characterise the ease of transfer of waste from the heap to targets.

Two approaches are tested here to characterise the risk of slope failure. The first one follows the protocol while the second refines the height criteria with information on slope stability.

First, as proposed by the AHG, the risk is quantified based on the height of the heap: higher heaps are more prone to geotechnical instability (question Q9 of the protocol). The threshold value of $20 \mathrm{~m}$ is derived from Irish guidelines for safety in quarries (as quoted by the Health and Safety Executive, 1999). A numerical model of the ground surface with a spatial resolution of $10 \mathrm{~m}$ (ERRUISSOL model, information on geoportail.wallonie.be) was used to compute heap height. Heap base elevation is estimated by interpolating between elevation values along heap perimeter. Heap height is the maximum value of the difference between surface and base elevation. The distribution of height values is shown on Figure 1. Only about $40 \%$ of the heaps have a height larger than the threshold value of $20 \mathrm{~m}$.

However, the physical mechanisms leading to slope failure do not depend on heap height. Hence, a criterion based on heap height merely takes into account that the impact in case of slope failure is increased. Instead, as a second approach, it is proposed to characterise the risk of failure with a criterion based on a geotechnical factor of safety. A factor of safety is generally defined as the ratio of a maximum admissible load and the load value actually applied on the slope (i.e. corresponding to heap weight and external loads). If the internal grain cohesion of the waste material is neglected, it can be shown that the factor of safety of an infinite dry slope can be computed based on:

$$
F=\frac{\tan \phi^{\prime}}{\tan \beta}
$$

Where:

$$
\begin{aligned}
& \phi^{\prime}\left[^{\circ}\right]=\text { internal friction angle of the waste material. } \\
& \beta\left[^{\circ}\right]=\text { slope angle. }
\end{aligned}
$$

Hence, intrinsic slope stability (i.e. $F \geq 1$ ) is ensured as long as the slope angle is smaller than the internal friction angle of the waste material. A criterion linked to slope angle is physically based and will provide an improved characterisation of the risk of slope failure compared with a criterion based on heap height.

To measure this criterion, it is possible to compute a factor of safety for each pixel of the numerical model of the ground surface based on Eq. (1). Coal mine waste materials are generally shale rock debris of relatively coarse granulometry (from $2 \mathrm{~mm}$ to $20 \mathrm{~cm}$ ) that could be characterised by friction angle values larger than $35^{\circ}$. A value of $35^{\circ}$ is adopted here. It is considered that the risk of geotechnical failure exists as soon as one pixel is characterised by $F<1$. This criterion considers that landslides of a surface area smaller than $100 \mathrm{~m}^{2}$ (i.e. one pixel of $10 \times 10 \mathrm{~m}$ ) have a negligible impact. Figure 1 shows the cumulative distribution of the percentage of the heap surface area for which $F<1$. 
Out of a total of 277 coal heaps, 261 do not pose any risk of local slope failure. This figure shows the importance of adopting a more-sophisticated and physically based approach when adequate data are available: risk assessment can be conducted without adopting exaggerated factors of safety and can lead to a realistic and reasonable characterisation of the level of risk.

Finally, the slope of the heap ground foundation (question Q10 of the initial protocol) is used to characterise the risk of a global landslide of the heap. This slope is the slope of the ground surface before the waste facility existed. The latter is estimated from the numerical model of the ground surface by interpolating between elevation values along the perimeter of the heap. A mean slope is estimated by fitting a plane to the interpolated elevation values. The threshold value of $1 / 12$ is that proposed in the Health and Safety Executive (1999). Figure 2 shows the distribution of values of foundation slope for Walloon coal heaps. A total of 233 of them are located in areas where the initial slope values of the ground surface were below $1 / 12$.

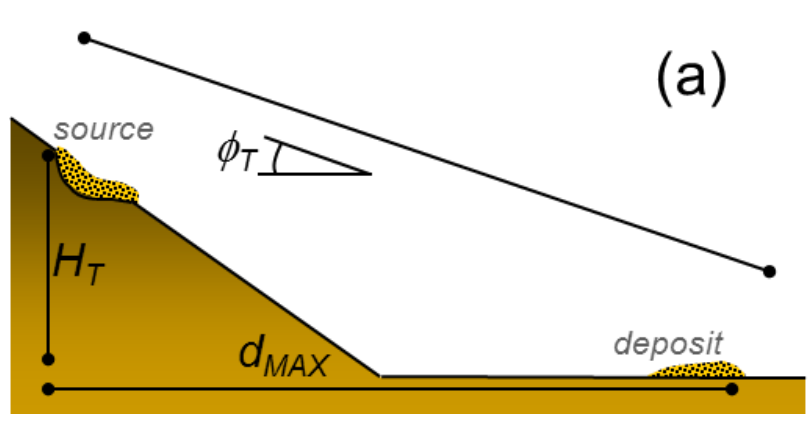

Figure 2 (a) Definition of the angle of reach of a landslide; (b) Comparison of field data reported by Corominas (1996) and Hungr et al. (2002) to the simplified relationships used here, assuming landslides of a volume corresponding to $10 \%$ of the total volume of waste stored in the facilities

\subsubsection{Targets}

\subsubsection{Threshold distance}

The default threshold distance proposed by Stanley et al. (2011) in the initial protocol is $1 \mathrm{~km}$. Corominas (1996) and Hungr et al. (2002) conducted reviews of literature data on landslides and showed that the impact distance can be correlated to the volume of waste and to the topography of the landscape. The angle of reach $\phi_{T}$ is defined from the ratio of the vertical projection to the horizontal projection of the distance covered by the debris mobilised during the landslide (Figure 2) as:

$$
\tan \phi_{T}=\frac{H_{T}}{d_{\max }}
$$

Where:

$$
\begin{aligned}
& H_{T}[\mathrm{~m}]=\text { vertical projection of the distance covered by the landslide. } \\
& d_{\max }[\mathrm{m}]=\text { horizontal projection of the distance covered by the landslide. }
\end{aligned}
$$

A low angle of reach will characterise a landslide of high mobility. This characterisation has the advantage of being easy to obtain on the basis of field surveys. In the context of risk assessment, the angle of reach is directly related to the size of the area potentially impacted by the landslide. 
Corominas (1996) and Hungr et al. (2002) studied the correlation between the angle of reach and the volume of moving debris based on literature data on actual landslides. They both systematically observed that landslides with a larger volume of debris are characterised by a lower angle of reach. Data reported in Corominas (1996) and Hungr et al. (2002) relate angle of reach to volume of moving debris. Assuming that the volume of moving debris corresponds to an arbitrary but safe value of $10 \%$ of the total volume of waste, their original data can be converted to link angle of reach to the total volume of waste stored in the facility (Figure 2). Based on that converted data, the following relationships are proposed to compute the maximum impact distance in case of a landslide:

- For a facility containing a volume of waste of less than $1,000 \mathrm{~m}^{3}$, the maximum impact distance is computed as 1.5 times heap height.

- For a facility containing a volume of waste between 1,000 and $1,000,000 \mathrm{~m}^{3}$, the maximum impact distance is computed as 3 times heap height.

- For a facility containing a volume of waste larger than $1,000,000 \mathrm{~m}^{3}$, the maximum impact distance is computed as 6 times heap height.

As compared to literature data reported by Corominas (1996) and Hungr et al. (2002), these relationships provide values of the angle of reach that are in the very low range of observed values in actual cases of landslides (Figure 2). The relationships are thus considered providing realistic but safe approximations of the impact distances. As heap volume can be computed based on the numerical model of the ground surface and on the estimated elevation of the ground before the heap existed, the relationships can be used to compute heap-specific impact distances. Figure 3 shows the distribution of impact distance for Walloon coal heaps. About $80 \%$ of coal heaps have a landslide impact distance lower than $150 \mathrm{~m}$, and the maximum impact distance is on the order of $540 \mathrm{~m}$, which are much lower values than the threshold of $1 \mathrm{~km}$ proposed by the initial protocol.

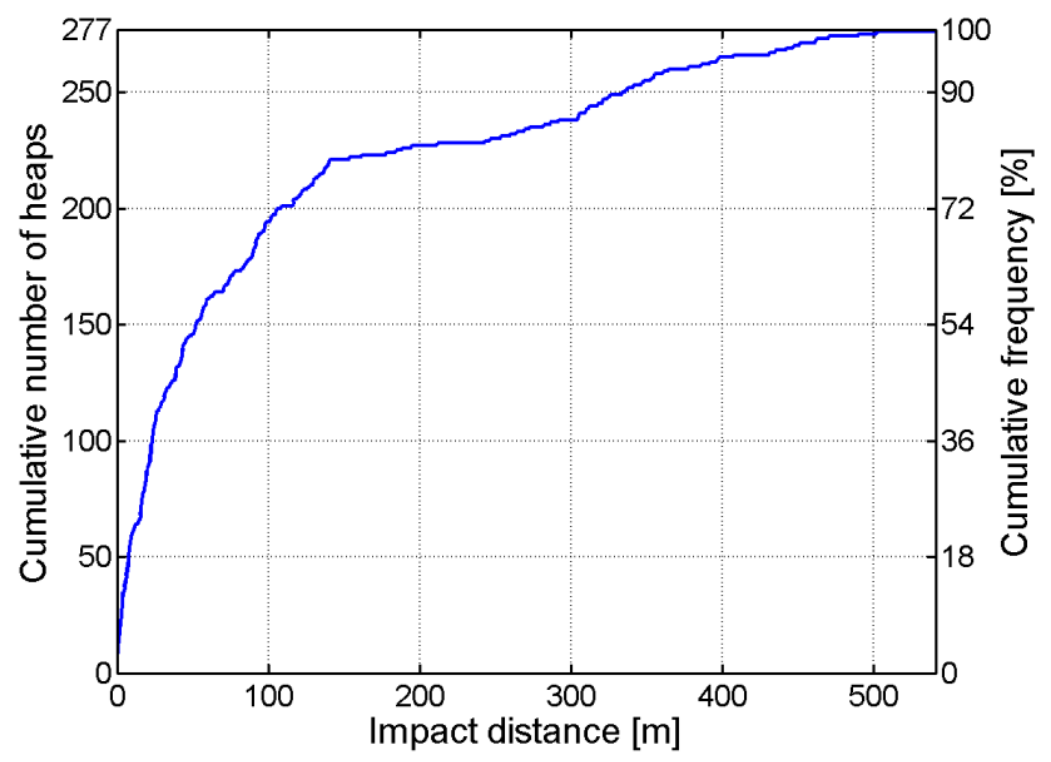

Figure 3 Cumulative distribution of landslide impact distances determined, based on heap volume and height

\subsubsection{Types of target}

Three specific types of target are considered here: human population (question Q15 of the initial protocol), watercourses (question Q11) and Natura 2000 sites. The occurrence of a landslide indeed threatens the life of humans present within the landslide pathway. The European map of population density (publicly available at www.eea.europa.eu) provided by the European Environment Agency disaggregates population statistics based on land use data. 
The disaggregation method uses weights corresponding to areas where population resides (urban) and does not reside (agricultural areas, natural vegetation, water or forest). The spatial resolution of this database is $100 \mathrm{~m}$. It allows a direct identification of human settlements of more than 100 people, called here 'populated centres', as proposed by the protocol. Only a single coal heap has its closest human settlement of more than 100 people at a distance larger than $1 \mathrm{~km}$ (Figure 4). Among the 276 other heaps, 220 are located in the direct vicinity of a large human settlement. In the Walloon region, urban areas mainly developed near mining and industrial sites, where work used to be available. The proposed threshold distance for the perimeter where populated centres have to be sought is critical in this case and should be decreased, as it currently includes most of the Walloon Region population. Considering the limited size of the territory and its generally high population density, choosing a threshold value of $1 \mathrm{~km}$ fails to reduce the number of WFs needing further risk assessment.
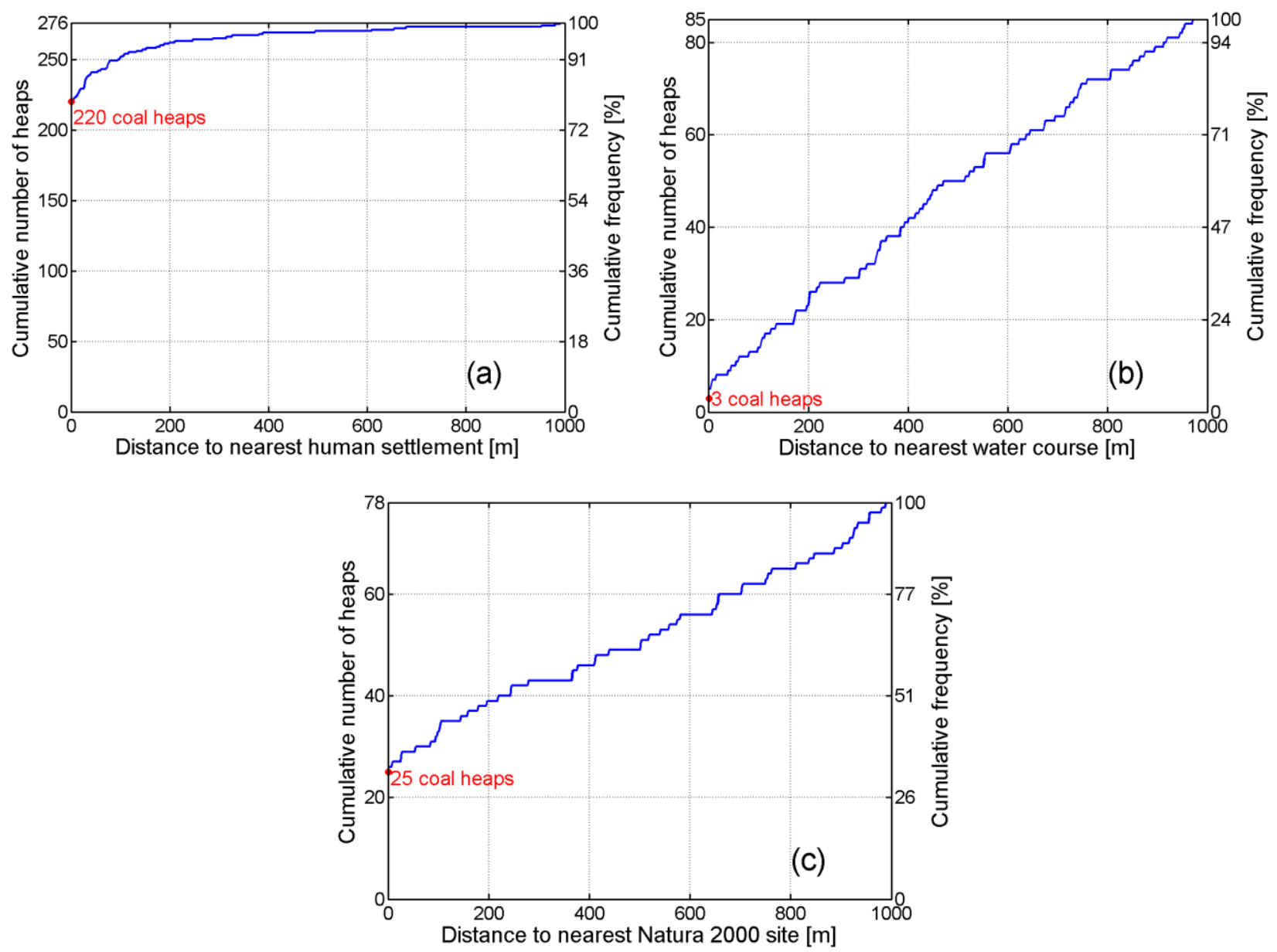

Figure 4 Cumulative distributions of distances to the nearest targets (targets within less than $1 \mathrm{~km}$ only); (a) human settlements of more than 100 inhabitant; (b) watercourses; and (c) Natura 2000 sites

Second, watercourses are considered here as targets, as their environmental quality (e.g., turbidity) can be significantly altered if it is reached by waste material mobilised during a landslide. In the original protocol, watercourses were rather considered as vectors of chemical pollution towards potential targets located downstream. The database of watercourses used here was provided by the Service Public de Wallonie. In order to match the spatial resolution criteria proposed in the initial protocol, only the main watercourses are considered here. Figure 4 show the cumulative distribution of distances to the closest watercourse, for distances smaller than the threshold value of $1 \mathrm{~km}$ proposed in the initial protocol. Only 85 coal heaps have a watercourse within a $1 \mathrm{~km}$ distance. Three of them are located directly on the pathway of a watercourse. 
Finally, the third type of targets considered here is Natura 2000 sites, which can be significantly altered by the occurrence of a landslide (e.g., destruction of vegetation, of animal habitats). The database used here is a GIS shapefile of georeferenced polygons depicting the limits of Natura 2000 sites, available from the European Environment Agency (www.eea.europa.eu). The cumulative distribution of distances to the closest Natura 2000 site is shown in Figure 4(c): 78 coal heaps are located closer than the threshold value of $1 \mathrm{~km}$ as proposed by the initial protocol, while 25 Natura 2000 sites are in direct contact with a coal heap.

Agricultural lands (question Q18 of the protocol) are not considered as adequate targets in the event of a loss of geotechnical stability. Indeed, a landslide will generally have a relatively limited impact on culture or on a prairie farm (mainly covering of the land by waste material). The agricultural zone will generally be easily rehabilitated by removing the waste material if such an incident occurred. The study does not consider, therefore, that a landslide would significantly impact any agricultural land.

\subsection{Risk assessment}

Two distinct methodologies are proposed to integrate risk components and perform the screening among Walloon coal heaps. The first flowchart only uses criteria proposed by Stanley et al. (2011) (Figure 5a). The method is, however, more elaborated than that of the initial protocol, as it only associates criteria relevant with the type of impact under consideration. While the initial protocol proposes using each criterion individually to select the WF, which means that each factor is combined to the other with an 'or' as logical operator, this methodology uses the conjunction operator 'and'. In the second flow chart, the new criteria and threshold values are combined in order to improve the characterisation of the pathway and target components (Figure 5b).

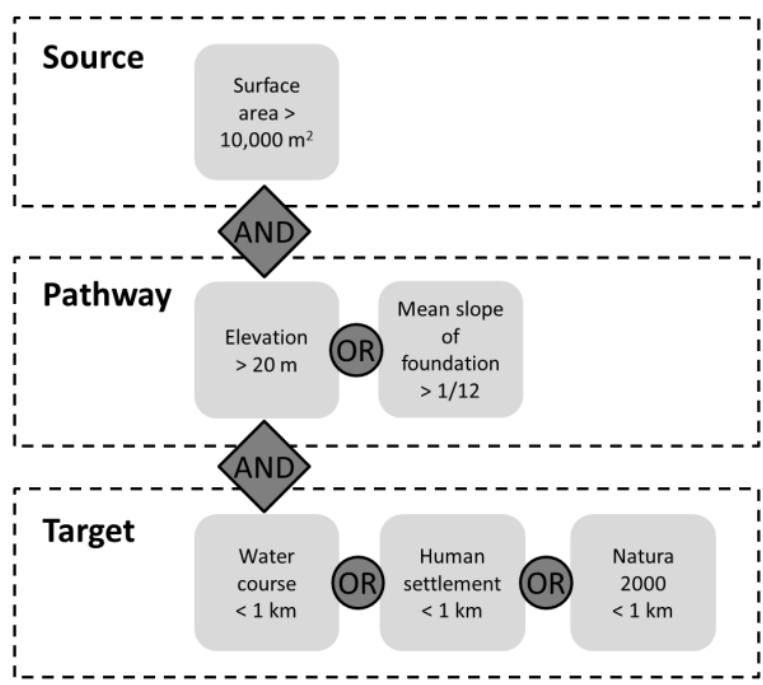

(a)

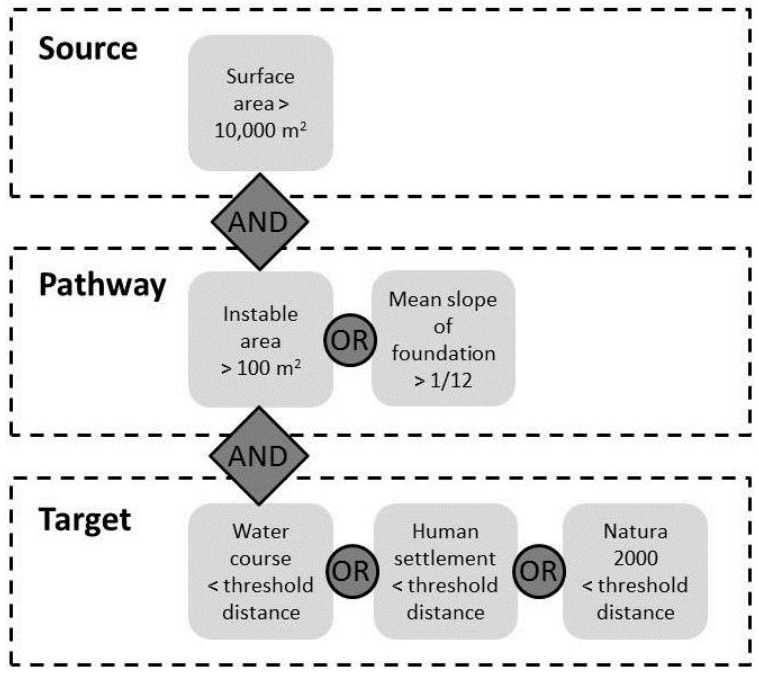

(b)

Figure 5 Flowcharts for the assessment of the risk of geotechnical failure; (a) methodology based on the initial protocol as proposed by Stanley et al. (2011); (b) taking into account a geotechnical criterion for stability and realistic impact distances

The application of the first flowchart leads to the screening out of 26 coal heaps and retains 251 heaps for further risk analysis. The criteria of the original protocol, while simple and based on easily accessible data, do not allow an efficient screening of the waste facilities, and the pre-selection protocol fails to meet its main objective of decreasing the number of WFs to be further analysed and integrated in the complete inventory. Application of the second flow chart leads to the screening out of 247 heaps, leading to the need to further examine only 30 sites. This shows that, when data are available, a closer characterisation of the physical mechanisms influencing the level of risk allows a more accurate assessment. 


\section{Conclusions}

This paper describes and discusses a pre-selection protocol based on the method proposed by the AHG for the inventory of the risks associated with abandoned and/or closed mine waste facilities. The initial protocol of the AHG combined in a single flowchart a series of 18 questions based on relatively coarse-scale data. It was designed as a screening tool allowing the identification of waste facilities not posing any serious threat to humans or the environment.

The pre-selection protocol was applied to Walloon coal mine waste facilities. In this case, other types of mine waste facilities (i.e., metal mine waste facilities and WFs of quarries) could be directly excluded from the inventory either because of their very limited size and a thorough manual extraction of any residual ore or because the presence of potential contaminants could be excluded based on the nature of the extracted materials and the mining process.

While the pre-selection protocol was simple and precautionary, it did not allow an efficient screening of Walloon coal mine waste facilities, leading to a result where most of them are considered as needing further risk assessment. Hence, the protocol was adapted to better account for specific Walloon conditions. While the Walloon protocol is essentially based on the same series of questions as the initial protocol of the AHG, they are now combined in five risk-specific flowcharts. For each type of risk - risk for the air, risk for water resources, risk for the soil, risk linked to direct contact with the waste material or risk of geotechnical failure - specific criteria are used to describe the source, pathway and target components of the risk assessment. When appropriate fine-scale data were available, new criteria were also used, as compared with the initial protocol.

As an example of the application of the modified methodology, the assessment of the risk of geotechnical failure is presented. Due to the nature of the mining industry, this type of risk proved to be the main risk associated to Walloon mining waste facilities. Its assessment is partly based on a series of new criteria, including physically based slope stability criteria. The threshold values beyond which no impact is expected were also modified based on literature data of actual landslides. From the initial set of 277 Walloon coal waste facilities, 247 could be screened out based on the modified protocol. Only 30 facilities will require further risk assessment studies.

\section{References}

Corominas, J. (1996) The angle of reach as a mobility index for small and large landslides, Canadian Geotechnical Journal, Vol. 33, pp. 260-271.

European Commission (2009) Decision 2009/337/EC of 20 April 2009 on the Definition of the Criteria for the Classification of Waste Facilities in Accordance with Annex III of Directive 2006/21/EC of the European Parliament and of the Council concerning the Management of Waste from Extractive Industries (notified under document number C(2009) 2856).

European Parliament and Council (2006) Directive 2006/21/EC of 15 March 2006 on the Management of Waste from Extractive Industries and Amending Directive 2004/35/EC, Statement by the European Parliament, the Council and the Commission.

Health and Safety Executive (1999) Health and Safety at Quarries, Quarries Regulation 1999, Approved Code of Practice, UK, $100 \mathrm{p}$.

Hungr, O., Dawson, R., Kent, A., Campbell, D. and Morgenstern, N.R. (2002) Rapid flow slides of coal-mine waste in British Colombia, Canada, in Catastrophic Landslides: Effects, Occurrence and Mechanisms, S.G. Evans and J.V. DeGraff (eds), Geological Society of America Reviews in Engineering Geology XV.

Stanley, G., Jordan, G. and Hamor, T. (2011) Guidance Document for a Risk-based Pre-selection Protocol for the Inventory of Closed Waste Facilities as Required by Article 20 of Directive 2006/21/EC.

Stephenne, N., Frippiat, C., Veschkens, M. and Pacyna, D. (2013) From European to regional management of mining waste deposits: adapting to Walloon specificities, in Proceedings of the 33ed EARSel Symposium, 3-6 June, Matera, Italy. 
